\title{
Thermal effects in high density polyethylene and low density polyethylene at high hydrostatic pressures
}

\author{
E. L. RODRIGUEZ \\ Owens-Corning Fiberglas Corporation, Technical Center, Granville, Ohio 43023, USA \\ F. E. FILISKO \\ Department of Materials and Metallurgical Engineering, Macromolecular Research Center, \\ The University of Michigan, Ann Arbor, Michigan 48104, USA
}

The temperature changes as a result of rapid hydrostatic pressure applications are reported for high density polyethylene (HDPE) and low density polyethylene (LDPE) in the reference temperature range from 298 to $423 \mathrm{~K}$ and in the pressure range from 13.8 to $200 \mathrm{MN} \mathrm{m}^{-2}$. The adiabatic temperature changes were found to be a function of pressure and temperature. $A$ curve fitting analysis showed that the empirical curve $(\partial T / \partial P)=a b(\Delta P)^{b^{-1}}$ described the experimental thermoelastic coefficients obtained from the experiments. The data were analyzed by determining the predicted thermoelastic coefficients derived from the Thomson equation $(\partial T / \partial P)_{\theta}=\alpha T_{0} / \varrho C_{p}$. The experimental and predicted Grüneisen parameter $\gamma_{T}$ were also determined.

\section{Introduction}

Polyethylene thermoplastics have been widely studied in many aspects because of their large number of industrial applications [1, 2]. Pressure and temperature are usually required for molding these materials. For example, in injection molding a pressure range from 55.16 to $207 \mathrm{MN} \mathrm{m}^{-2}$ is employed and a temperature range from 149 to $315^{\circ} \mathrm{C}$ is in general required [3].

Two methods could be used during these pressure applications. First, the isothermal method where the specimen is maintained in equilibrium with the surroundings by slowly deforming it. Second, the adiabatic method where the rapid application of pressure results in a temperature change in the specimen. In an injection or compression moulding operation it is most likely that the process is conducted adiabatically, where the rapid applications of pressure are required to achieve the desired production rate. Another interesting observation is that most of the pressure-volume-temperature relationship necessary to characterize any thermoplastics are usually done isothermally.

Recently we have been studying the adiabatic method where the rapid applications of hydrostatic pressures result in temperature changes in the material. This adiabatic method is found to be a function on the type of deformation which may be tensile, compression, or hydrostatic pressure (volumetric). The classical example for adiabatic heating can be found in rubber and steel. For instance, the sudden stretching of a strip of rubber results in a rise of temperature whereas a sudden stretching of a steel bar results in a decrease in temperature [4-6].
Thermoelastic measurements (adiabatic heating) have been reported in glassy polymers during rapid uniaxial tension and rapid uniaxial compression [7-9]. We have also measured the thermoelastic effect in polymethylmethacrylate using hydrostatic pressures at different temperatures $[10,11]$. One of the benefits obtained from the thermoelastic measurements is that important thermodynamic variables such as the Grüneisen parameter could be estimated. The use of hydrostatic pressure deformation is a very attractive tool to study thermal effects, because other important factors, such as shear or plastic deformation, can be substantially minimized in the material [12].

This work reports the finding of an experimental investigation on the temperature changes occurring during rapid applications of hydrostatic pressure in low density polyethylene (LDPE) and high density polyethylene (HDPE). Temperature changes were measured at different reference temperature and for different pressure applications.

\section{Experimental procedure}

The HDPE and LDPE samples were obtained from the Cadillac Plastic and Chemical Company, Detroit, Michigan, as cylindrical rods of average dimensions 0.25 inches o.d. and 3.6 inches long $(0.635 \mathrm{~cm}$ o.d. and $9.14 \mathrm{~cm}$ long). The HDPE and LDPE samples were used as received. The molecular weight and molecular distribution were unknown. The values of the heat capacity, the thermal expansion coefficient and the density were obtained from Cadillac Plastics [13]. These values were reconfirmed from data available in the literature [3].

The apparatus and evaluation procedure for 


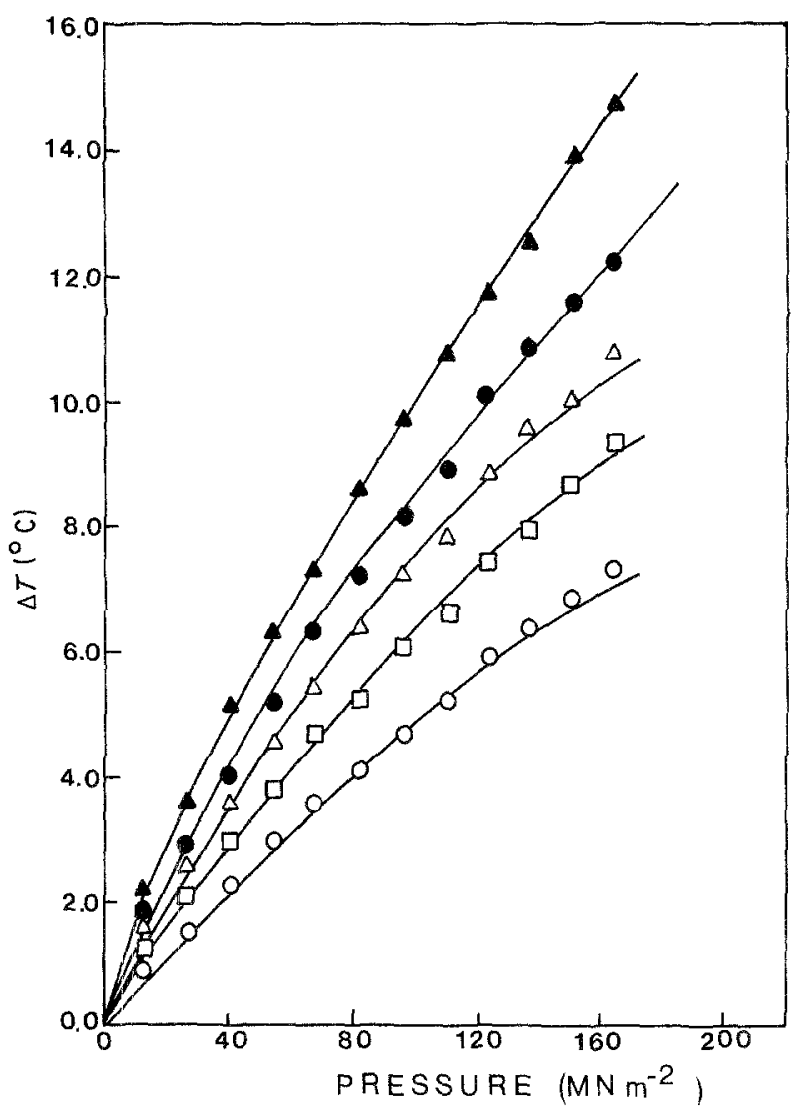

Figure 1 Temperature changes as a function of applied pressures for HDPE at different reference temperatures. (^) $389.0 \mathrm{~K},(\bullet) 373.0 \mathrm{~K}$,

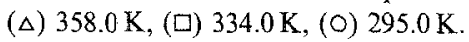

obtaining the temperature changes resulting from the rapid application of pressure were described previously $[10,14]$. Liquid mercury was used to transmit the pressure to the sample. Hydrostatic pressures were achieved by using a one horsepower air compressor and an air driven, high pressure reciprocating pump. The pressure was measured with two Bourdon gauges, each with a maximum of $345 \mathrm{MN} \mathrm{m}^{-2}$ and sensitivity of $3.45 \mathrm{MN} \mathrm{m}^{-2}$. The temperature changes were recorded using two iron-constantan thermocouples. The measuring junction was located in the geometric centre of the thermoplastic samples whereas the reference junction was located outside the high pressure unit. This arrangement allowed us to measure directly only the pressure variations and with maximum sensitivity, since when both junctions were at atmospheric pressure, the output of the differential thermocouple was virtually zero.

To record the adiabatic temperature changes, the system was allowed to equilibrate to atmospheric pressure and to the reference temperature. Pressure was rapidly applied by opening a high pressure valve which caused the selected pressure to be transmitted instantaneously to the sample. An increase in temperature was recorded. The pressure was released by the rapid opening of a second high pressure valve to atmospheric pressure which resulted in a decrease in temperature in the polyethylene samples.

\section{Results and discussion}

Figs 1 and 2 show the temperature changes as a function of the applied pressure at different tempera-

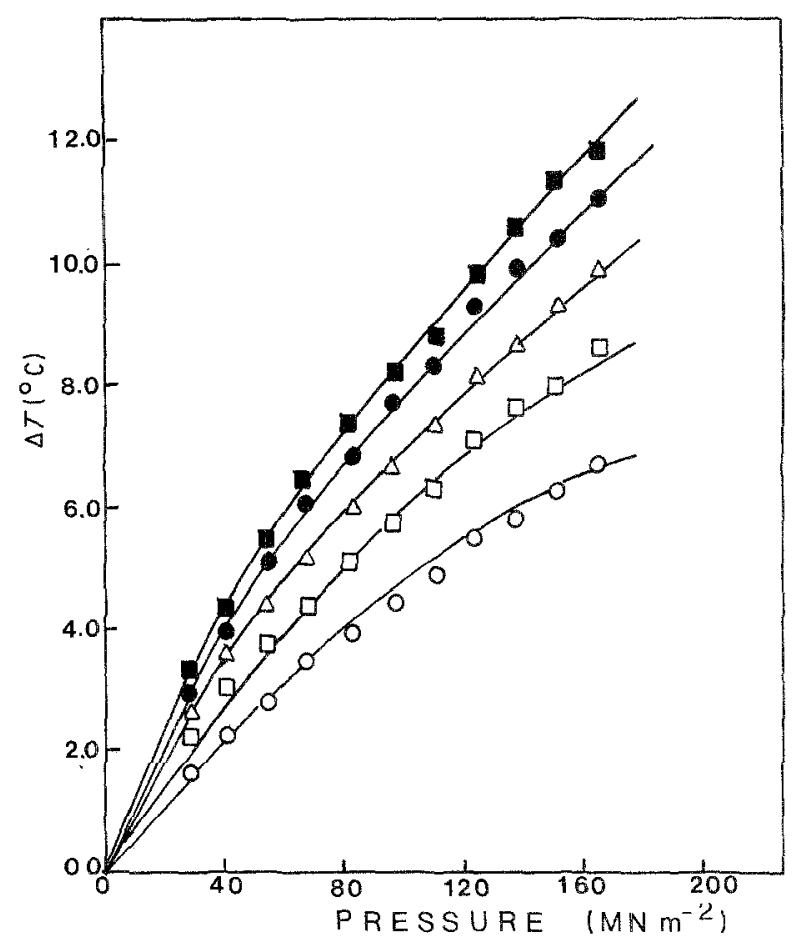

Figure 2 Temperature changes as a function of applied pressures for LDPE at different reference temperatures. ( $387.0 \mathrm{~K}$, ( $377.0 \mathrm{~K}$, (ه) $360.0 \mathrm{~K},(\square) 338.0 \mathrm{~K},(\mathrm{O}) 297.0 \mathrm{~K}$.

tures for HDPE and LDPE, respectively. The data is presented only for positive $\Delta P^{\prime} \mathrm{s}$ and thus positive temperature changes. The magnitude of the temperature changes were found to be significant for both HDPE and LDPE. The magnitude of the temperature changes increased with the pressure applied and with the reference temperature.

Figs 3 and 4 show the dependence of the temperature changes on the reference temperature at selected pressure for HDPE and LDPE, respectively. Figs 1 to 4 clearly show that the adiabatic temperature changes were a function of both pressure applied and the reference temperature. A curve fitting analysis showed that the adiabatic temperature changes as a function of pressure could be described through the empirical equation $\Delta T=a(\Delta P)^{b}$, where $a$ and $b$ are constants. Table I shows the results of the curve analysis: $\Delta T=T-T_{0}$ and $\Delta P=P-P_{0}$ where $T_{0}$ is the reference temperature and $P_{0}$ is the atmospheric pressure. The experimental thermoelastic coefficients $(\partial T / \partial P)_{\theta}$ were determined by differentiating on

TABLE I Values for $a$ and $b$ in the empirical equation $\Delta T=a(\Delta P)^{b}$ obtained from the curve fitting analysis

\begin{tabular}{llll}
\hline $\begin{array}{l}\text { Reference } \\
\text { temperature }(\mathbf{K})\end{array}$ & $a$ & $b$ & $\begin{array}{l}\text { Coefficient of } \\
\text { determination } R^{2}\end{array}$ \\
\hline HDPE & & & \\
299.5 & 0.1005 & 0.8409 & 0.99 \\
334.0 & 0.1521 & 0.8040 & 0.99 \\
358.0 & 0.1837 & 0.7993 & 1.00 \\
373.0 & 0.2269 & 0.7830 & 1.00 \\
389.0 & 0.2826 & 0.7725 & 1.00 \\
LDPE & & & \\
297.0 & 0.1232 & 0.7827 & 1.00 \\
338.0 & 0.1231 & 0.8419 & 1.00 \\
360.0 & 0.2168 & 0.7471 & 1.00 \\
377.0 & 0.2611 & 0.7363 & 1.00 \\
387.0 & 0.2986 & 0.7220 & 1.00 \\
\hline
\end{tabular}




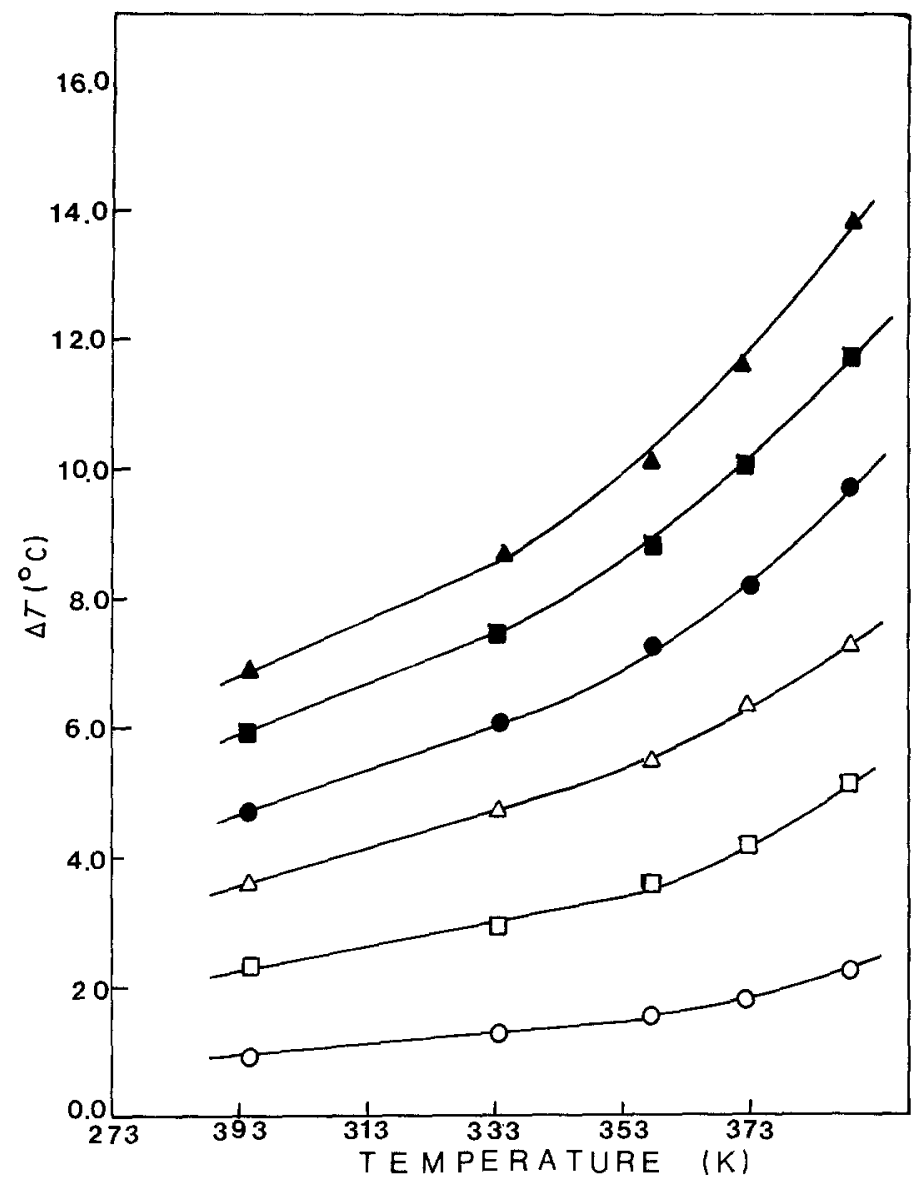

Figure 3 Temperature changes as a function of the reference temperature for HDPE at selected applied pressures (ム)

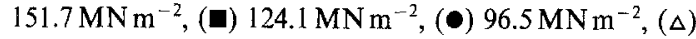
$69.0 \mathrm{MN} \mathrm{m}^{-2}$, (口) $41.4 \mathrm{MN} \mathrm{m}^{-2}$, (O) $13.8 \mathrm{MN} \mathrm{m}^{-2}$.

both sides the above empirical equation to obtain $(\partial T / \partial P)_{\theta}=a b(\Delta P)^{b-1}$.

This equation shows a dependence of the thermoelastic coefficients on the pressure applied. This equation is purely empirical and further evaluation was not conducted to correlate it with thermodynamic variables. Table II gives the numerical expressions for $(\partial T / \partial P)_{\theta}$ at certain reference temperatures and shows the thermoelastic coefficients determined from selected pressures at the same reference temperature.

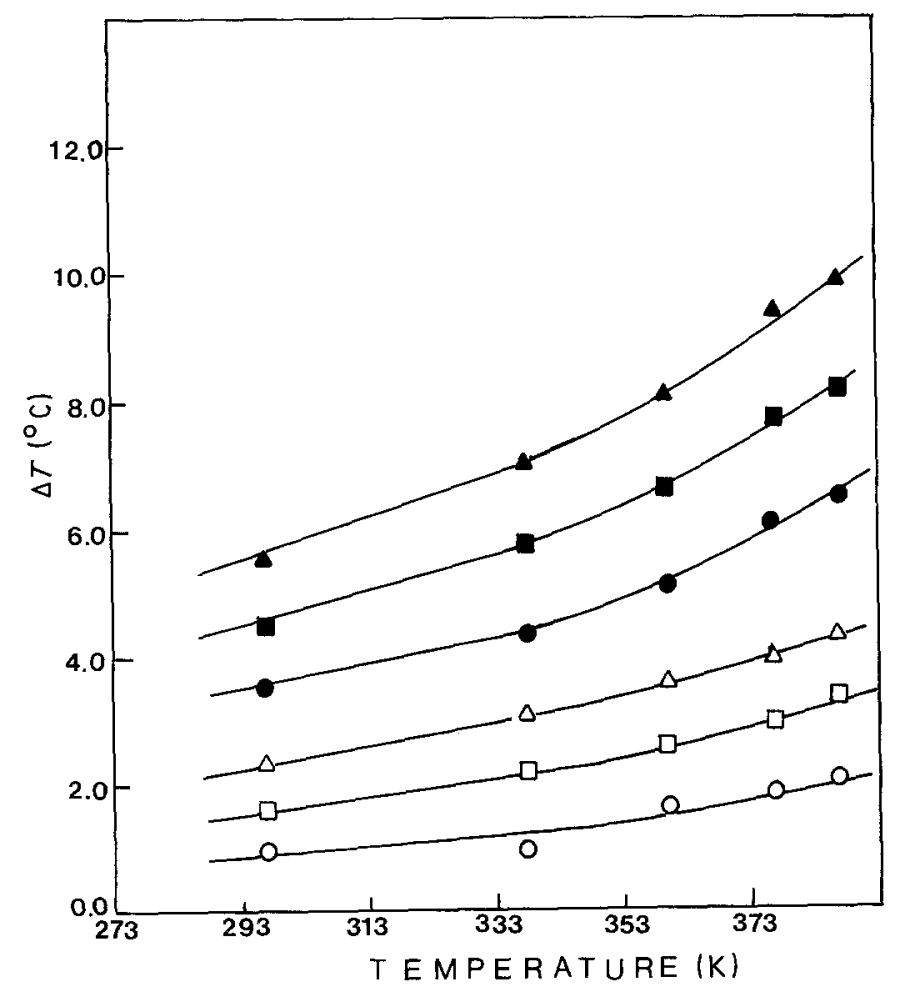

Thomson (Lord Kelvin) formulated the dynamic theory of heat [15]. A general expression describing the thermal effects associated with elastic deformations was derived from that theory. He also [16] proposed a general thermodynamic formula which describes the change in temperature as the result of the rapid application of pressure on fluids and observed that the adiabatic compression of a fluid (water and mercury) resulted in a rise in temperature.

Later Joule [17, 18] verified Thomson's equation
Figure 4 Temperature changes as a function of the reference temperature for LDPE at selected applied pressures. ( $\downarrow$ ) 124.1 $\mathrm{MN} \mathrm{m}^{-2}$, (ब) $96.5 \mathrm{MN} \mathrm{m}^{-2},(\bullet) 69.0 \mathrm{MN} \mathrm{m}^{-2},(\Delta)$ $41.4 \mathrm{MN} \mathrm{m}^{-2}$, (ㅁ) 27.6, (O) $13.8 \mathrm{MN} \mathrm{m}^{-2}$. 
TABLE II Experimental thermoelastic coefficients $(\partial T / \partial P)$ determined for HDPE and LDPE at selected pressures

\begin{tabular}{|c|c|c|c|}
\hline $\begin{array}{l}\text { Reference } \\
\text { temperature } \\
\text { (K) }\end{array}$ & $(\partial T / \partial P)_{\theta}=a b(\Delta P)^{b-1}$ & $\begin{array}{l}\Delta P \\
\left(\mathrm{MN} \mathrm{m}^{-2}\right)\end{array}$ & $\begin{array}{l}(\partial T / \partial P)_{\theta} \\
\left(\mathrm{K} / \mathrm{MN} \mathrm{m}^{-2}\right)\end{array}$ \\
\hline$\frac{\text { HDPE }}{295}$ & $0.08451(\Delta P)^{-0.1591}$ & $\begin{array}{l}0.1013 \\
4.0 \\
20 \\
100\end{array}$ & $\begin{array}{l}0.1217 \\
0.0678 \\
0.0525 \\
0.0406\end{array}$ \\
\hline 334 & $0.1223(\Delta P)^{-0.1960}$ & $\begin{array}{c}0.1013 \\
4.0 \\
20 \\
100\end{array}$ & $\begin{array}{l}0.1916 \\
0.0932 \\
0.0680 \\
0.0500\end{array}$ \\
\hline 358 & $0.1468 \times(\Delta P)^{-0.2010}$ & $\begin{array}{l}0.1013 \\
4.0 \\
20 \\
100\end{array}$ & $\begin{array}{l}0.2325 \\
0.1112 \\
0.0805 \\
0.0583\end{array}$ \\
\hline 373 & $0.1777(\Delta P)^{-0.2170}$ & $\begin{array}{l}0.1013 \\
4.0 \\
20 \\
100\end{array}$ & $\begin{array}{l}0.2920 \\
0.1315 \\
0.0927 \\
0.0654\end{array}$ \\
\hline 389 & $0.21831(\Delta P)^{-0.228}$ & $\begin{array}{l}0.1013 \\
4.0 \\
20 \\
100\end{array}$ & $\begin{array}{l}0.3680 \\
0.1593 \\
0.1104 \\
0.0766\end{array}$ \\
\hline$\frac{\text { LDPE }}{297}$ & $0.0964(\Delta P)^{-0.2173}$ & $\begin{array}{l}0.1013 \\
4.0 \\
20 \\
100\end{array}$ & $\begin{array}{l}0.1580 \\
0.0714 \\
0.0503 \\
0.0355\end{array}$ \\
\hline 338 & $0.1021(\Delta P)^{-0.1581}$ & $\begin{array}{l}0.1013 \\
4.0 \\
20 \\
100\end{array}$ & $\begin{array}{l}0.1470 \\
0.0820 \\
0.0636 \\
0.0493\end{array}$ \\
\hline 360 & $0.1620(\Delta P)^{-0.2530}$ & $\begin{array}{l}0.1013 \\
4.0 \\
20 \\
100\end{array}$ & $\begin{array}{l}0.2890 \\
0.1141 \\
0.0759 \\
0.0505\end{array}$ \\
\hline 377 & $0.1923(\Delta P)^{-0.2637}$ & $\begin{array}{l}0.1013 \\
4.0 \\
20 \\
100\end{array}$ & $\begin{array}{l}0.3516 \\
0.1334 \\
0.0873 \\
0.0571\end{array}$ \\
\hline 387 & $0.2156(\Delta P)^{-0.2780}$ & $\begin{array}{c}0.1013 \\
4.0 \\
20 \\
100\end{array}$ & $\begin{array}{l}0.4075 \\
0.1470 \\
0.0937 \\
0.0599\end{array}$ \\
\hline
\end{tabular}

by measuring the temperature changes produced by suddenly stretching or compressing a variety of materials including various liquids, metals, and rubber. Joule found that for low stresses, the measured temperature changes agreed with the predicted ones from the Thomson equation. Swallin [19] has shown a recent and modern derivation of the Thomson equation to describe the thermoelastic effect. For hydrostatic pressures, the Thomson equation can be written as:

$$
\left(\frac{\partial T}{\partial P}\right)_{\theta}=\frac{\alpha_{v} T_{0}}{\varrho C_{p}}
$$

where $\alpha_{v}$ is the volume thermal expansion coefficient, $C_{\mathrm{p}}$ is the specific heat at constant pressure, and $\varrho$ is the density. Usually the volume thermal expansion coefficient is approximate to $\alpha_{v}=3 \alpha_{L}$ where $\alpha_{L}$ is the linear thermal expansion coefficient. The term $(\partial T / \partial P)_{\theta}$ is usually defined as the thermoelastic coefficient.
TABLE III Physical data for HDPE and LDPE

\begin{tabular}{|c|c|c|c|}
\hline $\begin{array}{l}\text { Specific } \\
\text { gravity } \\
\left(\mathrm{kg} \mathrm{m}^{-3}\right)\end{array}$ & $\begin{array}{l}\text { Specific } \\
\text { heat } \\
(\mathrm{J} / \mathrm{kg} \mathrm{K})\end{array}$ & $\begin{array}{l}\text { Volumetric* } \\
\text { thermal } \\
\text { expansion } \\
(\mathrm{l} / \mathrm{K})\end{array}$ & $\begin{array}{l}\text { Thermoelastic }{ }^{\dagger} \\
\text { coefficient }(\partial T / \partial P)_{\theta} \\
\left(\mathrm{K} / \mathrm{MN} \mathrm{m}^{-2}\right)\end{array}$ \\
\hline
\end{tabular}

HDPE

\begin{tabular}{lllll}
\hline $0.953 \times 10^{3}$ & $2.303 \times 10^{3}$ & $3.6 \times 10^{-4}$ & $T_{0}=295 \mathrm{~K}$ & 0.0484 \\
{$[20]$} & {$[21,22,23]$} & {$[24]$} & $T_{0}=334 \mathrm{~K}$ & 0.0548 \\
& & & $T_{0}=358 \mathrm{~K}$ & 0.0587 \\
& & & $T_{0}=373 \mathrm{~K}$ & 0.0612 \\
& & & $T_{0}=389 \mathrm{~K}$ & 0.0638
\end{tabular}

\begin{tabular}{|c|c|c|c|c|}
\hline LDPE & & & & \\
\hline $0.918 \times 10^{3}$ & $1.916 \times 10^{3}$ & $5.1 \times 10^{-4}$ & $T_{0}=297 \mathrm{~K}$ & 0.086 \\
\hline [20] & [23] & {$[24]$} & $T_{0}=338 \mathrm{~K}$ & 0.098 \\
\hline & & & $T_{0}=360 \mathrm{~K}$ & 0.104 \\
\hline & & & $T_{0}=377 \mathrm{~K}$ & 0.109 \\
\hline & & & $T_{0}=387 \mathrm{~K}$ & 0.112 \\
\hline
\end{tabular}

$* \alpha_{v}=3 \alpha_{L}$

$\dagger$ Calculated from $(\partial T / \partial P)_{0}=\alpha_{\nu} T_{0} / \varrho C_{p}$, at atmospheric pressure.

To compare our experimental thermoelastic coefficient with the ones predicted using the Thomson equation, the values of the thermal expansion coefficient, the specific gravity, and the heat capacity for HDPE and LDPE were taken from different sources and they are shown in Table III. This data was confirmed by the table of physical properties provided by Cadillac Plastics Company [24], and others [25].

From Table II and Table III, the experimental and predicted thermoelastic coefficients $(\partial T / \partial P)$ were found to be slightly higher for LDPE than for HDPE. This is associated to the contribution from the thermal expansion coefficient where $\alpha_{v, \mathrm{LDPE}}>\alpha_{v, \mathrm{HDPE}}$. Thus the adiabatic temperature changes were found to be slightly higher for LDPE than for HDPE.

For materials of low molecular weight, it is frequently assumed that the volume thermal expansion coefficient, $\alpha_{v}$, the density, $\varrho$, and the heat capacity, $C_{\mathbf{p}}$, are not strongly dependent on pressure. In polymers the opposite has been found [26-29]. Two recent reviews $[30,31]$ have summarized the effects of hydrostatic pressures on the specific volume, glass and melting transitions, crystallization, and mechanical properties of polymers. Zoller [32] found that the specific volume increases with temperature and decreases with an increase in hydrostatic pressure for LDPE. Heylemann and Houck [33] measured the density and the isothermal bulk modulus of a LDPE at $23^{\circ} \mathrm{C}$ and at different hydrostatic pressures. They found that the density and the isothermal bulk modulus increase with pressure. The thermal expansion coefficient of polymers was found to increase with temperature and to decrease with pressure [34].

The pressure and temperature dependence found on the experimental $(\partial T / \partial P)$ values suggest that the term $\alpha_{v} / \varrho C_{p}$ in the Thomson equation is a function of both pressure and temperature. Similar results were found by other authors $[7]$ in polymethylmethacrylate where the thermoelastic coefficients obtained from uniaxial tension and compression measurements were used to evaluate the pressure and temperature dependence on the $\alpha_{v}$ and $C_{p}$ parameters. 
TA B LE IV Values of the Grüneisen constant for HDPE

\begin{tabular}{|c|c|c|c|}
\hline \multirow[t]{2}{*}{$\begin{array}{l}\text { Temperature } \\
\text { (K) }\end{array}$} & \multicolumn{2}{|c|}{$\begin{array}{l}\text { From experimental } \\
\text { thermoelastic } \\
\text { coefficients }\end{array}$} & \multirow{2}{*}{$\begin{array}{l}\text { Predicted values } \\
\text { from the Thomson } \\
\text { equation } \\
\gamma_{T}\end{array}$} \\
\hline & $\begin{array}{l}\Delta P \\
\left(\mathrm{MN} \mathrm{m}^{-2}\right)\end{array}$ & $\gamma_{T}$ & \\
\hline 295 & $\begin{array}{l}0.1013 \\
4 \\
20 \\
100\end{array}$ & $\begin{array}{l}2.06 \\
1.15 \\
0.89 \\
0.67\end{array}$ & 0.75 \\
\hline 334 & $\begin{array}{l}0.1013 \\
4 \\
20 \\
100\end{array}$ & $\begin{array}{l}2.87 \\
1.40 \\
1.02 \\
0.75\end{array}$ & 0.74 \\
\hline 358 & $\begin{array}{l}0.1013 \\
4 \\
20 \\
100\end{array}$ & $\begin{array}{l}3.25 \\
1.56 \\
1.12 \\
0.81\end{array}$ & 0.73 \\
\hline 373 & $\begin{array}{l}0.1013 \\
4 \\
20 \\
100\end{array}$ & $\begin{array}{l}3.91 \\
1.76 \\
1.24 \\
0.87\end{array}$ & 0.72 \\
\hline 389 & $\begin{array}{l}0.1013 \\
4 \\
20 \\
100\end{array}$ & $\begin{array}{l}4.73 \\
2.05 \\
1.42 \\
0.98\end{array}$ & 0.72 \\
\hline
\end{tabular}

Examining Tables II and III, differences were found between the predicted thermoelastic coefficients and the experimental ones at different temperatures and pressures. This indicates that care should be taken in applying thermodynamic variables that are well established for non-viscoelastic materials on reversible thermodynamics.

Several authors have used the thermoelastic method (adiabatic heating) to determine important thermodynamic properties. Kennedy et al. $[35,36]$ determined the pressure dependence of the Grüneisen parameter in different inorganic materials. Bottani et al., $[37,38]$ measured the Grüneisen parameter and the thermal diffusivity coefficient of titanium and steel using the temperature increments obtained from rapid compression. Haward et al., [7] reported values of the linear coefficient of expansion and the Grüneisen coefficient at different stresses and temperatures in poly(methyl methacrylate) from thermoelastic experiments during uniaxial tension and compression. Similar calculations have been done for glassy polymers $[8,9]$.

The macroscopic or the thermodynamic Grüneisen relationship $\gamma_{T}$ can be estimated from the thermoelastic coefficient $(\partial T / \partial P)_{\theta}$ through the equation:

$$
\gamma_{T}=\left(\frac{\partial T}{\partial P}\right)_{\theta} \frac{B_{\mathrm{s}}}{T}=\left(\frac{\partial T}{\partial P}\right)_{\theta} \frac{1}{T} B_{T} \frac{C_{p}}{C_{v}}
$$

where $B_{\mathrm{s}}$ is the adiabatic bulk modulus, $B_{T}$ is the isothermal bulk modulus, $C_{v}$ is the specific heat at constant volume and $C_{p}$ is the specific heat at constant pressure. The derivation of these relationships can be found in the literature [19]. The ratio $C_{v} / C_{p}$ can be determined from reversing the thermodynamics equation,

$$
C_{v}=C_{p}-T_{\alpha_{v}^{2}} B_{T} / \varrho
$$

\begin{tabular}{|c|c|c|c|}
\hline \multirow[t]{2}{*}{$\begin{array}{l}\text { Temperature } \\
\text { (K) }\end{array}$} & \multicolumn{2}{|c|}{$\begin{array}{l}\text { From experimental } \\
\text { thermoelastic } \\
\text { coefficients }\end{array}$} & \multirow{2}{*}{$\begin{array}{l}\text { Predicted values } \\
\text { from the Thomson } \\
\text { equation } \\
\gamma_{T}\end{array}$} \\
\hline & $\begin{array}{l}\Delta P \\
\left(\mathrm{MN} \mathrm{m}^{-2}\right)\end{array}$ & $\gamma_{T}$ & \\
\hline 297 & $\begin{array}{l}0.1013 \\
4 \\
20 \\
100\end{array}$ & $\begin{array}{l}1.81 \\
0.82 \\
0.58 \\
0.41\end{array}$ & 0.831 \\
\hline 338 & $\begin{array}{l}0.1013 \\
4 \\
20 \\
100\end{array}$ & $\begin{array}{l}1.48 \\
0.83 \\
0.64 \\
0.49\end{array}$ & 0.815 \\
\hline 360 & $\begin{array}{l}0.1013 \\
4 \\
20 \\
100\end{array}$ & $\begin{array}{l}2.73 \\
1.08 \\
0.72 \\
0.48\end{array}$ & 0.813 \\
\hline 377 & $\begin{array}{l}0.1013 \\
4 \\
20 \\
100\end{array}$ & $\begin{array}{l}3.17 \\
1.20 \\
0.79 \\
0.52\end{array}$ & 0.797 \\
\hline 387 & $\begin{array}{l}0.1013 \\
4 \\
20 \\
100\end{array}$ & $\begin{array}{l}3.60 \\
1.30 \\
0.82 \\
0.53\end{array}$ & 0.798 \\
\hline
\end{tabular}

TABLE V Values of the Grüneisen constant for LDPE

therefore allowing the determination of the Grüneisen coefficient.

For HDPE the isothermal bulk modulus reported in the literature is $5.0 \times 10^{3} \mathrm{MN} \mathrm{m}^{-2}$ whereas for LDPE the isothermal bulk modulus is $3.4 \times 10^{3} \mathrm{MN} \mathrm{m}^{-2}$ [39-41]. Using the experimental values and the predicted values from the Thomson equation for the thermoelastic coefficients, the Grüneisen parameter was calculated and the results are shown in Table IV and Table $\mathrm{V}$ for HDPE and LDPE respectively. The Grüneisen parameter was found to be a function of pressure and temperature. Fig. 5 illustrates the temperature dependence on the $\gamma_{T}$ values determined from the thermoelastic coefficients at selected pressures, and the predicted ones.

In addition, the value of the Grüneisen parameters decreased with pressure at constant temperature and increases with temperature at constant pressure. The predicted $\gamma_{T}$ from the Thomson equation were almost independent on the reference temperature. It is well established that the Grüneisen coefficient gives an estimation between the mechanical and heat effects in the material during deformation [19].

Warfield [42] reported the Grüneisen constant of polymers using pressure dependence of the bulk modulus. The lattice Grüneisen constant $\gamma_{L}$ is usually measured in these types of experiments which relate to the polymer chains moving in relation to each other (interchain motion). In our case the thermoelastic experiments are related to the thermodynamic Grüneisen constant $\gamma_{T}$ which is an average over all vibrations. Warfield [42] reported $\gamma_{L}=4.1$ and $\gamma_{T}=6.4$ for HDPE and LDPE respectively. He also determined the $\gamma_{T}$ values for HDPE $\left(\gamma_{T}=0.52\right)$ and LDPE $\left(\gamma_{r}=0.38\right)$. Thus, differences were found between our experimental values for $\gamma_{T}$ and the ones 


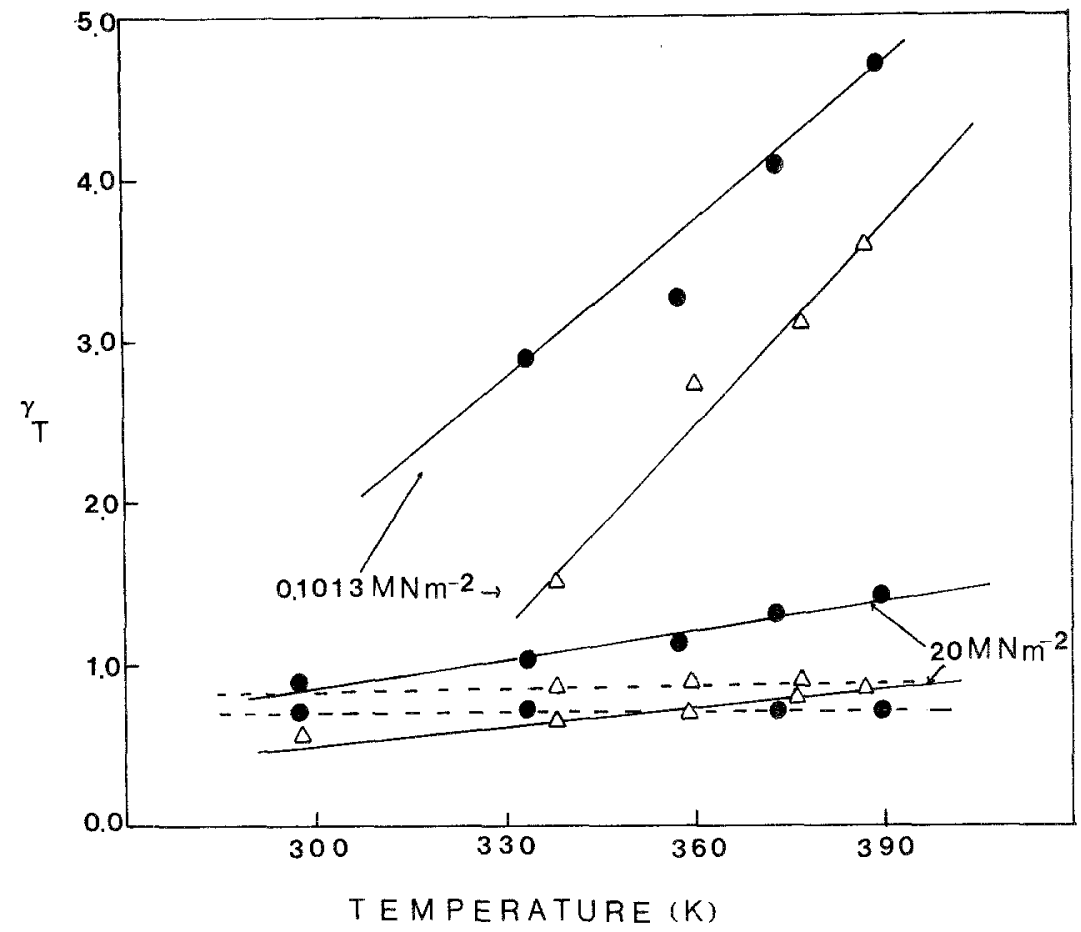

Figure 5 The macroscopic Grüneisen constant $\gamma_{T}$ as a function of the reference temperature for HDPE (- - ) and LDPE $(-\Delta-)$ Experimental values $(-)$ obtained from the thermoelastic coefficients and predicted values (--) determined from the Thomson equation.

reported by Warfield [42]. These differences may be related to the $\alpha_{v}, C_{p}$ and $\varrho$ parameters used in the calculations and in the different materials used in the experiments. Other authors have reported a $\gamma_{T}=1.1$ for HDPE [43-45] which are closer to our experimental values.

\section{Conclusion}

To conclude, the thermoelastic method (adiabatic heating), during rapid application of pressures, affords a new method to determine important thermodynamic variables for viscoelastic materials. The simplicity of the experiment reported here may suggest a quick way to evaluate the pressure and temperature dependence of an important physical parameter for polymers.

\section{References}

1. J. H. DUBOIS and F. W. JOHN, "Plastics", 5th Edn (Van Nostrand Reinhold Co., New York, 1974).

2. S. S. SCHWARTZ and S. H. GOODMAN, "Plastics Materials and Processes" (Van Nostran Reinhold Co., New York, 1982)

3. R. A. RAFF, in "Encyclopedia of Polymer Science and Technology, Vol. 6", edited by H. F. Mark, N. G. Gaylor and N. M. Bikales (Wiley-Interscience, New York, 1967) 304

4. J. GOUGH, Proc, Lit. and Phil. Soc. Manchester, $2 \mathrm{~d}$ Ser. 1 (1805) 288.

5. R. ROCCA and M. B. BEVER, Trans. AIME, 188 (1950) 323.

6. F. H. MÜLLER, in "Rheology Theory and Applications", Volume 5 edited by F. R. Eirich (Academic Press, New York, 1969) Ch. 8.

7. R. N. HAWARD and A. TRAINOR, J. Mater. Sci. 9 (1974) 1243

8. I. W. GILMOUR, A. TRAINOR and R. N. HAWARD, J. Polym. Sci. Polym. Phys. Edn 16 (1978) 1277.

9. Idem, ibid. 16 (1978) 1291.

10. E. L. RODRIGUEZ and F. E. FILISKO, J. Appl. Phys. 53 (1982) 6536.

11. E. L. RODRIGUEZ, J. Mater. Sci. Lett. 5 (1986) 481.

12. R. A. DUCKETT and S. H. JOSEPH, Polymer 17 (1976) 329.

13. "Plastic and Safety Buyer's Guide", edited by Cadillac Plastics and Chemical Co. (1980) p. I14.
14. E. L. RODRIGUEZ and F. E. FILISKO, J. Mater. Sci. Lett. 5 (1986) 225.

15. W. THOMSON (Lord Kelvin), Trans. Roy. Soc. Edinburgh, March (1851).

16. Idem, Proc. R. Soc. June (1857)

17. J, P. JOULE, ibid. 8 (1857) 355.

18. Idem, Phil. Trans. 149 (1859) 91

19. R. A. SWALIN, "Thermodynamics of Solids", 2nd edn, (Wiley-Interscience, New York, 1972) p. 33

20. K. W. DOAK and A. SCHRAGE, in "Crystalline Olefin Polymers", Part I, edited by R. A. V. Raff and K. W. Doaff, (Interscience, New York, 1965) 301.

21. E. PASSAGLIA and H. K. KEVORKIAN, J. Appl. Polym. Sci. 7 (1963) 119.

22. W. REESE and J. E. TUCKER, J. Chem. Phys. 43 (1965) 105

23. J. E. TUCKER and W. REESE, ibid. 46 (1967) 1388.

24. "Table of Physical Properties for Plastic Materials", edited by Cadillac Plastics Company (1980).

25. P. D. RITCHIE (ed) "Vinyl and Allied Polymers", Vol. (Ilifle, London 1968).

26. R. M. KiMMEL and D. R. Uhlmann, J. Appl. Phys. 41 (1970) 2917

27. J. B. YOURTEE and S. L. COOPER, J. Appl. Polym Sci. 18 (1974) 897.

28. P. ANDERSON and B. SUNDAVIST, J. Polym. Sci. Phys. Ed. 13 (1975) 243.

29. M. V. BELOSTOTSKII, B. A. ARUYUNOV, V. S BIL and R. D. STEPANOV, Mekhanika Polimerov 1 (1977) 163.

30. K. D, PAE and S. K. BHATEJA, J. Macromol, Sci. C13 (1975) 1.

31. S. K. BHATEJA and K. D. PAE, ibid. C13 (1975) 77

32. P. ZOLler, J. Appl. Polym. Sci. 23 (1979) 1051.

33. P. L. HEYDEMANN and J. C. HOUCK, $J$. Polym. Sci. Polym. Phys. Ed. 10 (1972) 1631.

34. P. L. HEYDEMANN and H. D. GUICKING, Kolloid-Z 193 (1963) I6

35. J, RAMAKRISHNAN and G. KENNEDY, $J . P h s_{s}$ Chem. Solids 41 (1980) 301.

36. R. BOEHLER, I. GETTING and G. C. KENNEDY, ibid. 38 (1977) 233.

37. C. E. BOtTANI, G. CAGLIOTI, A. NOVELLI and P. M. OSSI, Appl. Phys. 18 (1979) 63.

38. M. BEGHI and C. E. BOTTANI, ibid. 23 (1980) 57.

39. R. W. WARFIELD, S. E. CUEVAS and F. R BARNET, J. Appl. Polym. Sci. 12 (1968) 1147. 
40. R, W. WARFIELD and F, R. BARNET, Makromol. Chem. 27 (1972) 215.

41. Idem, ibid. 44 (1975) 181.

42. R. W. WAR FIELD, Makromol. Chem. 175 (1974) 3285

43. M. SHEN, W. N. HANSEN and P. C. ROMO, J. Chem. Phys. 51 (1969) 425.

44. C. K. WU, G. JURA and M. SHEN, J. Appl. Phys. 43
(1972) 4348

45. M. SHEN, Polym. Eng. and Sci. 19 (1979) 995.

Received 3 July

and accepted 1 December 1986 